\title{
La Unión Europea y la gobernanza global del desarrollo
}

\section{The European Union and the Global Governance of Development}

\author{
José Ángel Sotillo Lorenzo ${ }^{1}$ \\ Universidad Complutense de Madrid (España)
}

Recibido: 10-02-17

Aprobado: 20-03-17

\section{Resumen}

$\mathrm{Si}$ entendemos por gobernanza una forma de gobierno que promueve el desarrollo desde una opción pluridimensional y de gestión democrática de políticas que tienen ese objetivo, la Unión Europea sería un ejemplo de gobernanza. Y lo sería en una doble dimensión: la interna y la externa, ya que propone ser un actor civil global. Dentro de su papel como actor internacional ocupa un lugar destacado la política de desarrollo, donde la Unión Europea actúa en consonancia con los Objetivos de Desarrollo Sostenible y la Agenda 2030 para transformar nuestro mundo. Pero el proceso de integración choca con varios obstáculos que ponen en cuestión ese objetivo, por lo que la Unión necesita de un nuevo impulso para hacer frente a los desafíos internos y a escala global.

Palabras-clave: Unión Europea, gobernanza, Cooperación Internacional, Objetivos de Desarrollo Sostenible.

\begin{abstract}
The European Union could be an example of governance because its government shears for development on a multidimensional level of democratic politics. And it is in two dimensions: domestic and external. In its role as an international actor, the European Union lines up with the UN 2030 Sustainable Development Goals to transform the world. But in the domestic scope, the European Union faces new obstacles and needs a new impetus to solve them.

\footnotetext{
${ }^{1}$ (sotillo@pdi.ucm.es) Profesor Titular del Departamento de Relaciones Internacionales en la Facultad de Ciencias Políticas y Sociología de la Universidad Complutense de Madrid. Es director del Instituto Universitario de Desarrollo y Cooperación (IUDC-UCM) y de la Revista Española de Desarrollo y Cooperación. Es doctor en Ciencias Políticas y Sociología por la Universidad Complutense de Madrid. Entre sus libros destaca: Un lugar en el mundo, 2006 y Antología del desarrollo, 2015.
} 
Key-words: European Union, Governance, International Cooperation, Sustainable Development Goals

\section{Introducción}

"Europa no se hará de una vez ni en una obra de conjunto: se hará gracias a realizaciones concretas, que creen en primer lugar una solidaridad de hecho", Robert Schuman, 9 de mayo de 1950. Esa frase pronunciada por el Ministro francés de Asuntos Exteriores como parte de la Declaración que expresa la naturaleza del proceso de integración europea, simboliza en buena medida como se gesta la gobernanza europea, donde el método supranacional creará vínculos y una forma de gestión conjunta por encima de los propios Estados miembros, habiendo dado éstos su consentimiento.

La Unión Europea se ha presentado como uno de los procesos de integración regional más avanzados del mundo; y, a su vez, como un referente internacional en el ámbito de la gobernanza. Calificado como actor sui géneris -al situarse en algo más que una forma de cooperación intergubernamental y algo menos que una forma federal- tanto por su método de trabajo, objetivos y funciones, toma de decisiones y su amplio ámbito de competencias, encaja en el perfil de gobernanza. Para analizar esa forma de gobernanza conocida como Unión Europea, examinamos primero el marco conceptual en el que se mueve ese término, especialmente desde las relaciones internacionales $\mathrm{y}$, más en concreto, desde la cooperación para el desarrollo. Desde ese marco aplicaremos la categoría de gobernanza al papel de la Unión Europea como actor internacional y en el ámbito concreto de la cooperación europea para el desarrollo. Por último, se tratará la situación del proceso de integración, cómo se ha visto afectado por las múltiples crisis que lo cuestionan y qué opciones se están manejando para su futuro.

En ese sentido, en el texto se combinará lo estructural -aquello que se interpreta como clave y permanente en el proceso de integración- con lo coyuntural -los hechos que afectan a la Unión en el momento actual-; el proceso de integración europea sigue recordando que una de las etimologías de Europa la asocia con el que ve a lo lejos, aunque la Unión Europea sigue siendo en la actualidad un proceso cargado de futuro -a su vez amenazado en varios frentes-, pero alterado por todos los cambios que vive en el presente. De ahí esta etapa de confusión que hace que la Unión Europea sea, como en la obra de Luigi Pirandelllo, como uno de sus seis personajes en busca de autor.

Con respecto al enfoque, fundamentalmente irá dirigido, dentro del marco de la Unión Europea como actor internacional sui géneris, al vínculo entre gobernanza, política exterior y cooperación para el desarrollo. En momentos 
de posverdades y verdades alternativas, la incertidumbre provocada por los vertiginosos cambios que vive la humanidad -acelerados por la violencia generalizada, el miedo que recorre el planeta, la simultaneidad de los hechos conflictivos que suceden y la instantaneidad de su información-, parecen afectar también a la incertidumbre y al pesimismo intelectual, con lo cual es más necesario que nunca buscar referentes; es ahí donde encontramos a autores como Tzvetan Todorov, Tony Judt o Zygmunt Bauman (Ceguera moral: la pérdida de sensibilidad en la modernidad líquida, 2015). Se trata, pues, de recuperar el pensamiento cosmopolita en un mundo caracterizado por la extensión de la violencia y, para ello, es necesario recuperar también el ideal europeo como actor que tiene como misión contribuir no sólo a la paz y el bienestar dentro del continente europeo, sino también corresponsabilizarse en la paz y el bienestar mundial.

\section{Revisando el concepto de gobernanza (desde las relaciones internacio- nales y la cooperación para el desarrollo)}

La gobernanza es un concepto incorporado a las Relaciones Internacionales, aunque también es parte de la terminología de otras ciencias, como la Ciencia Política. Su uso es tan amplio, confuso e indiscriminado que muchas veces se hace difícil comprender su significado; encaja en la definición de polisemia, en lo que se refiere a pluralidad de significados de una expresión lingüística. Un primer lugar al que acudir para descubrir qué significa esa palabra es el diccionario de la Real Academia Española que define gobernanza como "Arte o manera de gobernar que se propone como objetivo el logro de un desarrollo económico, social e institucional duradero, promoviendo un sano equilibrio entre el Estado, la sociedad civil y el mercado de la economía”.

Pero ya nos advertía Lewis Carroll, en Alicia a través del espejo, de la importancia y el poder que tienen los nombres. Desde el ámbito académico nos lo recordó el profesor José Vidal-Beneyto": "La palabra gobernanza, cuya primera aparición en el siglo XV es francesa bajo la forma de gouvernance, recala en el mundo anglosajón a finales del XVII -governance-, y desde entonces es de circulación habitual allí como sinónimo de ejercicio del poder, de actividad de gobierno. De forma inesperada, a mediados de los años ochenta irrumpe con fuerza en los ámbitos institucionales ligados a los problemas del desarrollo, en especial en las organizaciones económicas internacionales, con un significado nuevo y más preciso".

\footnotetext{
2 "Gobernabilidad y gobernanza", Tribuna: Las palabras del imperio (I), El País, 12 de abril de 2002.

Araucaria. Revista Iberoamericana de Filosofía, Política y Humanidades, año 19, n ${ }^{\circ} 37$. Primer semestre de 2017. Pp. 427-454. ISSN 1575-6823 e-ISSN 2340-2199 doi: 10.12795/araucaria.2017.i37.20
} 
Desde el siglo XV el concepto evoluciona hasta alcanzar el término de gobernanza híbrida que tratan Francesco Colona y Rivke Jaffe ${ }^{3}$, para mostrar la tendencia reciente en las políticas de desarrollo que involucra a actores más allá del Estado-nación, tales como empresas, ONG y otras autoridades menos formalizadas y locales.

Desde el Instituto Universitario de Desarrollo y Cooperación (IUDCUCM), al tratar esta problemática cuestión, se entiende que la gobernanza incluye las nuevas modalidades de dirección y coordinación intersectoriales entre políticas e intereses diversos y múltiples niveles que se observan tanto en el plano local como nacional e internacional, es decir, las diversas interacciones entre los actores políticos y sociales, públicos y privados, para la resolución de determinados problemas comunes. La gobernanza remite, en los discursos de las agencias internacionales, a la conformación de una articulación virtuosa entre el Estado, el mercado y la sociedad civil en el ámbito nacional, pero también a la coordinación de diversas estrategias e intereses en el marco global. La gobernanza global puede definirse como un modo pluralista de gestión de las interdependencias, un dispositivo pluralista que permite a la comunidad internacional tratar los problemas colectivos a los que se enfrenta.

Es necesario recordar que hay otras definiciones limitadas a aspectos formales (más cercanas a la gobernabilidad, a la gestión, y al peso del sector privado, vinculadas al New Public Managment). De este modo, se parte de una visión pluralista y democrática de la gobernanza, que asegure la inclusión de los diversos actores en la toma de decisiones, mejorando con ello la participación de los mismos, pero también la coordinación y la eficacia. Aun así, teniendo en cuenta el peligro de que la noción de gobernanza suele ocultar los conflictos de intereses, las contradicciones y la hegemonía, pone el acento sobre el consenso y no constituye una reflexión sobre el poder sino sobre los modos más eficientes de gestión de la sociedad.

Para Juan Sebastián Ortiz, "La gobernanza en las relaciones internacionales se refiere a la forma como las organizaciones e instituciones del sistema internacional gestionan los problemas transnacionales y los nuevos desafíos globales (cambio climático, crimen organizado, migraciones, pobreza, violencia, etc.) en una perspectiva que no sólo reconoce la cooperación entre Estados independientes, sino también, la actuación de cualquier otra colectividad o actor en los renovados esquemas de realismo multipolar" ${ }^{4}$.

Siguiendo a Van Kersbergen y Van Waarden ${ }^{5}$, otro de los ámbitos

3 "Hybrid Governance Arrangements" (2016), European Journal of Development Research, 28, abril, pp. 175-183.

${ }^{4}$ Ver el trabajo de Juan Sebastián Ortiz Martínez (2016): La gobernanza en la cooperación internacional para el desarrollo. Instituto Universitario de Desarrollo y Cooperación (IUDC-UCM), Documento de Trabajo n ${ }^{\circ}$ 38, septiembre 2016.

${ }^{5}$ Kees van Kersbergen Frans Van Waarden (2004): “'Governance' as a bridge between disciplines: Cross-disciplinary inspiration regarding shifts in governance and problems of governability, 
prioritarios es la gobernanza económica, que es una noción diferente que se origina a partir de los principios del neoinstitucionalismo económico y denota una situación en la que el mercado no es un orden social espontáneo y por lo tanto, debe ser creado y dirigido a partir de arreglos institucionales en los que se definen los derechos de propiedad, se promueve la competencia y se reducen los costos de transacción, los riesgos y la información asimétrica. La Unión encajaría en esa dualidad de gestión económica conjunta, pero carente de una gobernanza económica democrática. Ortiz resume en la siguiente tabla el concepto de gobernanza:

\section{Tabla 1. El concepto de la gobernanza}

\begin{tabular}{|c|c|}
\hline $\begin{array}{c}\text { Características } \\
\text { generales }\end{array}$ & $\begin{array}{l}\text { - Concepto utilizado para referirse a las manifestaciones empíricas de las } \\
\text { adaptaciones del Estado a los cambios sociales y económicos de su entorno } \\
\text { durante las últimas décadas del siglo XX. } \\
\text { - Representación teórica o conceptual de la forma como se vienen generando } \\
\text { los diferentes mecanismos de interacción y coordinación de los actores e } \\
\text { instituciones sociales en la acción de gobierno y del rol del Estado en dicho } \\
\text { proceso. } \\
\text { - Concepto que denota la existencia de nuevas dinámicas de gobierno en las } \\
\text { que el Estado deja de ser el actor monolítico de la acción pública y se reconoce } \\
\text { la presencia e influencia de otros actores en la acción de gobierno, a partir de } \\
\text { relaciones de interdependencia e interacción mutua entre las instituciones } \\
\text { políticas y la sociedad. }\end{array}$ \\
\hline Aproximaciones & $\begin{array}{l}\text { - Socio-céntrica: gobierno y dirección de la sociedad basados en esquemas con } \\
\text { una mínima o nula intervención del Estado y articulado en torno a } \\
\text { organizaciones sociales y/o el mercado. } \\
\text { - Estado-céntrica: reconocimiento del Estado como actor clave para la } \\
\text { dirección de la sociedad y la consecución bienestar e interés público }\end{array}$ \\
\hline $\begin{array}{c}\text { Usos y rasgos } \\
\text { específicos }\end{array}$ & $\begin{array}{l}\text { - Varía en función de las diferentes connotaciones del concepto: buena } \\
\text { gobernanza, gobernanza en las relaciones internacionales, gobernanza como } \\
\text { auto-organización social, gobernanza económica, gobernanza corporativa, } \\
\text { gobernanza democrática, gobernanza urbana y gobernanza multinivel. } \\
\text { - Énfasis en los procesos de la acción de gobierno en contraposición a su } \\
\text { estructura institucional, privilegiando la coordinación, negociación, formación } \\
\text { alianzas, etc., más que a los procesos tradicionales de coerción y control. } \\
\text { Señala la existencia de un complejo conjunto de instituciones y actores } \\
\text { públicos y privados que interactúan en el gobierno como acción e institución. } \\
\text { - Reconoce la presencia de una frontera difusa respecto a las competencias y } \\
\text { responsabilidades en la gestión de los problemas socioeconómicos. } \\
\text { - Noción pluricéntrica del poder y su distribución entre diversos actores } \\
\text { estatales y no estatales de los cuales se origina la acción de gobierno. } \\
\text { - Redes como instrumento preferente de la articulación y gestión de las } \\
\text { relaciones e interdependencia entre los actores públicos y privados. }\end{array}$ \\
\hline
\end{tabular}

Fuente: Juan Sebastián Ortiz Martínez (2016): La gobernanza en la cooperación internacional para el desarrollo. Instituto Universitario de Desarrollo y Cooperación (IUDC-UCM), Documento de Trabajo no 38, septiembre 2016, p. 20.

accountability and legitimacy", European Journal of Political Research, Vol. 43, 2, marzo 2004, pp. 143-171. Ver también Johan P. Olsen (2009): "Change and continuity: an institutional approach to institutions of democratic government, European Political Science Review, Vol. 1, 1, pp. 3-22; Rianne Mahon y Stephen MacBride (2009): "Standardizing and disseminating knowledge: the role of the OECD in global governance”, European Political Science Review, Vol. 1, 1, pp. 83-101. 
La gobernanza se ha convertido en las últimas décadas en un vocablo corriente en la terminología de las instituciones financieras internacionales, que emplea recurrentemente el concepto de gobernanza con un uso ideologizado en favor de la buena gestión tecnocrática, poniéndola en contraposición a los gobiernos fallidos. Anna Bruce-Lockhart, del World Economic Forum, en su artículo "What do we mean by 'governance"?", la identifica como una palabra de moda y señala sus principales características con el siguiente gráfico:

\section{Gráfico 1. Buena Gobernanza}

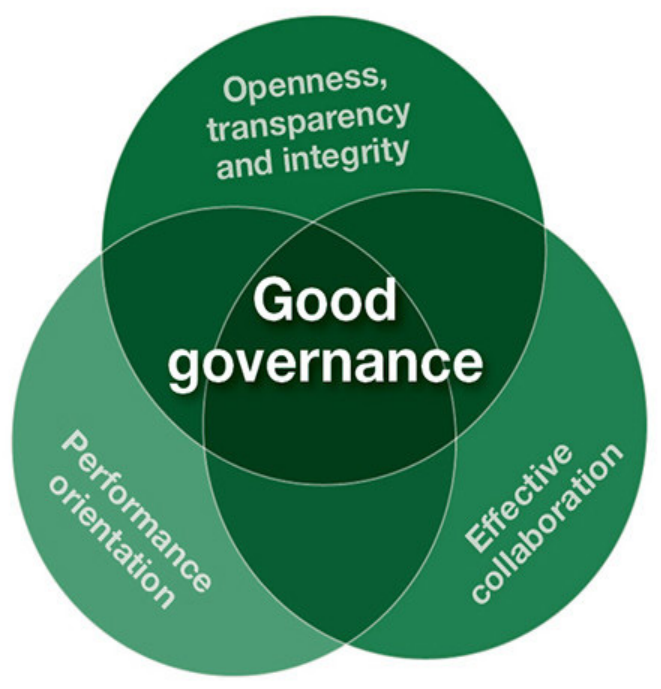

Una de las instituciones que ha venido utilizando la gobernanza como método de trabajo ha sido el Banco Mundial. En el "Informe sobre el desarrollo mundial 2017: La gobernanza y las leyes"”, se pregunta ¿por qué son ineficaces tantas políticas con buenas intenciones? Las políticas funcionan cuando se adaptan a las circunstancias cambiantes y cuando las personas deciden juntas

6 "Global governance, good governance, failing governance: like so many buzzwords in the field of international development, the word has come to mean different things to different groups", ver la página https:/www.weforum.org/agenda/2016/02/what-is-governance-and-why-does-it-matter?utm content=buffer $5 \mathrm{~b} 8 \mathrm{c} 4 \& u$ tm_medium $=$ social\&utm_source=facebook.com\&utm_campaign=buffer

7 Para lograr un buen desarrollo, la gobernanza cuenta, Enero 30, 2017, http://www.bancomundial. org/es/news/video/2017/01/30/wdr-2017-governance-and-the-law. El Informe sobre el desarrollo mundial 2017 relativo a la gobernanza y las leyes en 11 gráficos, por Tariq Khokhar, 31 de enero de 2017, https://blogs.worldbank.org/opendata/es/informe-sobre-el-desarrollo-mundial-2017-gobernanzay-las-leyes-en-graficos 
para beneficiar al bien común. Pero a veces la distribución desigual del poder puede socavar el compromiso, la coordinación y la cooperación. ¿Qué determina que las políticas públicas sean eficaces y beneficien a los ciudadanos? De acuerdo al Informe la respuesta a esta pregunta es mejorar la gobernanza, es decir el proceso mediante el cual los Gobiernos y los ciudadanos interactúan para diseñar y aplicar políticas.

Para Mariana Kaipper Ceratti, productora on line del Banco Mundial: "La distribución desigual del poder es una de las principales razones de por qué las políticas de desarrollo, aunque bien intencionadas, a menudo no mejoran la vida de las personas". Las 'asimetrías de poder' "pueden tener efectos negativos en las instituciones y políticas públicas, entre ellos, llevar al clientelismo, afectar a la prestación de servicios básicos, perjudicar a los pobres e incluso provocar respuestas violentas de los grupos que se sientan excluidos de la toma de decisiones" ". Destaca que compromiso (dejar que la política pública dure sin importar las circunstancias), coordinación (promueve acciones conjuntas basadas en expectativas compartidas) y cooperación (utiliza recompensas o castigos para limitar el comportamiento oportunista) son las tres claves de la gobernanza. El Banco Mundial elabora los Worldwide Governance Indicators $(\mathrm{WGI})^{9}$, que incluye tanto indicadores globales como individuales para más de 200 países en seis niveles principales de gobernanza: estabilidad política, ausencia de violencia, efectividad gubernamental, estado de derecho, control de la corrupción, la calidad de la regulación.

La relación entre la gobernanza de las instituciones y sus resultados son visibles en "The Governance Report", elaborado por la Hertie School of Governance y publicado por Oxford University Press desde 2013; en el Informe de 2016, se establece la relación en base a las variables de la gobernanza de las infraestructuras ${ }^{10}$. Esas tomas de posición sobre la gobernanza más cercanas a la gestión efectiva son criticadas por autores como Juan Carlos Monedero en su obra "La trampa de la gobernanza. Nuevas formas de participación política"11. "La hegemonía neoliberal impulsó, por su parte, una explicación del deterioro económico y político alcanzado en el último cuarto de siglo. En vez de atacar las causas estructurales se intentó encontrar responsables en sitios inverosímiles (la televisión, los inmigrantes, el intervencionismo estatal, el exceso de participación, etc.). En esa discusión empezaron a dejarse de lado

\footnotetext{
${ }^{8}$ Ver http://internacional.elpais.com/internacional/2017/01/31/actualidad/1485896171_296129.html

9 Ver la página http://info.worldbank.org/governance/wgi/\#home

${ }^{10}$ Ver más información en http://www.governancereport.org/en/home/governance-challenges/2016infrastructure/

${ }^{11} \mathrm{http}: / /$ www.2015ymas.org/IMG/pdf/Anuario 200302 E LATRAMPA.pdf. El gobierno de las palabras. Política para tiempos de confusión. Madrid, FCE, 2009; capítulo XI "La trampa de la gobernanza", pp. 69-184. Ver también Júlia Martí Comas (2016): "Gobernanza: la nueva matriz política del neoliberalismo", PAPELES de Relaciones Ecosociales y Cambio Global, Número 133, pp. 111-126.
} 
las preguntas clásicas sobre la legitimidad de la democracia o la superación del capitalismo, para dar entrada a conceptos como buen gobierno, gobernabilidad democrática, gobernanza y buena gobernanza, que sitúan en un segundo plano la cuestión del poder, los desmanes cometidos bajo el paraguas ideológico liberal y la ruptura del consenso social de posguerra. Esas carencias de lo sustantivo de la democracia intentaron solventarse con refuerzos adjetivos. La insatisfacción se expresó hablando de "déficit democrático", o adjetivando a la democracia como "delegativa", "de baja intensidad", "incompleta", "incierta" o, en la exacerbación de la paradoja, como "democracia autoritaria" (J. Nun). Pero la pregunta esencial (qué democracia) quedaba ausente del debate".

El vínculo entre la gobernanza internacional y la cooperación para el desarrollo, tomando como marco de referencia las ciencias sociales, es examinado por Bruno Ayllón de esta manera: "De las posibles definiciones, quizás sea la del Comité de Políticas de Desarrollo de la ONU, inspirada en la obra de James Rosenau, una de las más acertadas. El término "gobernanza" haría referencia a "(...) la regulación de relaciones interdependientes en ausencia de una autoridad política central, como en el sistema internacional. Incluye las instituciones, políticas, normas, procedimientos e iniciativas a través de las cuales los Estados y sus ciudadanos intentan alcanzar más predictibilidad, estabilidad y orden para sus respuestas a los desafíos trasnacionales"12.

Desde la Agencia Española de Cooperación Internacional para el Desarrollo (AECID), en la "Estrategia de Gobernabilidad Democrática, Participación Ciudadana y Desarrollo Institucional" 13, se plantea la gobernabilidad democrática desde un enfoque basado en una mejor relación entre el Estados y la sociedad, persiguiendo tres objetivos: "la profundización del régimen democrático; la institucionalización de normas y la reducción de incertidumbres o, lo que es lo mismo, la profundización en el Estado de Derecho; y la mejora del rendimiento económico y social".

12 "La Gobernanza de la Cooperación y el rol de las Organizaciones de la Sociedad Civil en la Cooperación Sur-Sur", Revista Internacional de Cooperación y Desarrollo, Vol. I, n. 2, juliodiciembre 2014, pp. 57-89.

${ }^{13}$ Estrategia de Gobernabilidad Democrática, Participación Ciudadana y Desarrollo Institucional, Dirección General de Planificación y Evaluación de Políticas para el Desarrollo, Secretaría de Estado de Cooperación Internacional, Ministerio de Asuntos Exteriores y de Cooperación, 2008. Elaboración y coordinación por Miguel Ángel Lombardo. 
Tabla 2. Un concepto amplio de gobernabilidad democrática.

Las variables que contempla la Estrategia de Gobernabilidad, quedan contempladas en la siguiente Tabla.

\begin{tabular}{|c|c|c|}
\hline $\begin{array}{l}\text { Profundización del } \\
\text { régimen democrático }\end{array}$ & $\begin{array}{l}\text { Institucionalización de normas y } \\
\text { reducción de incertidumbres }\end{array}$ & Rendimiento económico y social \\
\hline $\begin{array}{l}\text { ESTADO DEMOCRÁTICO - LEGITI- } \\
\text { MIDAD DE GOBIERNO E INSTITU- } \\
\text { CIONES PÚBLICAS }\end{array}$ & $\begin{array}{l}\text { ESTADO DE DERECHO - SEGURI- } \\
\text { DAD Y LIBERTAD PARA EJERCICIO } \\
\text { DE DERECHOS }\end{array}$ & $\begin{array}{l}\text { ESTADO SOCIAL - OPORTUNIDA- } \\
\text { DES A TRAVES DEL ACCESO ALOS } \\
\text { SERVICIOS BÁSICOS }\end{array}$ \\
\hline $\begin{array}{l}\text { Ampliación del apego a la ley y la ren- } \\
\text { dición de cuentas entre poderes y a la } \\
\text { ciudadanía }\end{array}$ & Consistencia de las prácticas políticas & $\begin{array}{l}\text { Beneficios derivados de la lucha contra } \\
\text { la corrupción y una apropiada fiscalidad } \\
\text { (mayores ingresos -tasas, impuestos- } \\
\text { mayor inversión privada, etc.) }\end{array}$ \\
\hline $\begin{array}{l}\text { Reducción de barreras institucionales } \\
\text { que limitan la participación política y la } \\
\text { movilización de los sectores sociales } \\
\text { marginados }\end{array}$ & Predictibilidad de las normas & $\begin{array}{l}\text { Resultados económicos y sociales del } \\
\text { intercambio político y sus efectos en la } \\
\text { estabilidad del sistema institucional }\end{array}$ \\
\hline Descentralización del poder & $\begin{array}{l}\text { Aceptación de la incertidumbre de los } \\
\text { resultados del juego democrático }\end{array}$ & $\begin{array}{l}\text { Estabilidad macroeconómica y elimi- } \\
\text { nación de la pobreza }\end{array}$ \\
\hline $\begin{array}{l}\text { Establecimiento de medios que garan- } \\
\text { ticen más espacio, energía y autono- } \\
\text { mía para la sociedad civil }\end{array}$ & $\begin{array}{l}\text { Estructuras politicas que permiten ejer- } \\
\text { cer adecuadamente la mediación de in- } \\
\text { tereses y la resolución de conflictos }\end{array}$ & $\begin{array}{l}\text { Reducción de conflictividad social, po- } \\
\text { sibilidad de pactos sociales, organiza- } \\
\text { ciones empresariales / organizaciones } \\
\text { sindicales / organizaciones de la eco- } \\
\text { nomía social }\end{array}$ \\
\hline $\begin{array}{l}\text { Protección efectiva de los derechos } \\
\text { políticos, sociales, económicos y civiles } \\
\text { de los ciudadanos y ciudadanas }\end{array}$ & $\begin{array}{l}\text { Grado de desarrollo de los partidos po- } \\
\text { líticos y de los agentes sociales y eco- } \\
\text { nómicos }\end{array}$ & $\begin{array}{l}\text { Reducción de la conflictividad social } \\
\text { mediante la inclusión de derechos de } \\
\text { minorías }\end{array}$ \\
\hline
\end{tabular}

Fuente: Estrategia de Gobernabilidad Democrática, Participación Ciudadana y Desarrollo Institucional, http://www.aecid.es/ES/sectores-de-cooperaci\%C3\%B3n/ gobernabilidad-democr\%C3\%A1tica, p. 27

Para la AECID se considera que "la democracia es un valor universal basado en el derecho de los pueblos a determinar su propio sistema político, económico, social y cultural. La Gobernabilidad democrática comienza con el derecho de las personas a elegir su camino hacia el desarrollo sostenible, y centra su atención no sólo en el rendimiento de las instituciones sino también en su legitimidad; adoptando para ello un enfoque basado en derechos universales en el que la ciudadanía es titular de los mismos. La Estrategia de la Cooperación Española en materia de Gobernabilidad democrática reconoce el derecho de las personas a tener un desarrollo sostenible, y señala que para ello las instituciones deben garantizar el acceso a servicios básicos, el disfrute de los derechos políticos y la igualdad de género; todo ello dentro del respeto a la soberanía de los países en los que la Cooperación Española interviene, y dentro del marco internacional que establecen los Derechos Humanos". 
Por su parte, José Antonio Ocampo plantea seis criterios básicos para redefinir la estructura mundial de la cooperación: "1. Aplicar sólidos principios de subsidiariedad; 2. Utilizar una amplia red de instituciones nacionales, regionales y mundiales; 3. Emplear órganos pequeños pero representativos para la toma de decisiones que ayuden a superar la tensión entre la integración y la eficacia; 4. Garantizar la participación equitativa de los países en desarrollo en la toma de decisiones; 5 . Utilizar instrumentos efectivos de supervisión de los compromisos internacionales, que deberían garantizar el cumplimiento en lo que respecta a los bienes públicos mundiales, y aplicar normas para garantizar el trato diferenciado de los países en desarrollo y mecanismos de rendición de cuentas no vinculantes -revisión por pares o comisiones similares a las creadas para la implementación de las convenciones internacionales sobre derechos humanos-, y 6. Garantizar la coherencia del sistema. En el último caso, se convoca a la transformación del G20 en el consejo de coordinación económica mundial propuesto por la Comisión de Expertos sobre las Reformas del Sistema Monetario y Financiero Internacional, o una institución similar, y al fortalecimiento de las funciones del Consejo Económico y Social en el área de política y en el seguimiento de las conferencias mundiales, como foro principal de cooperación para el desarrollo y como coordinador de la cooperación y de otros temas específicos del sistema de Naciones Unidas." 14

En esa misma obra sobre Gobernanza Globaly desarrollo. Nuevos desafios y prioridades de la cooperación internacional, José Antonio Alonso afirma que "La gobernanza del sistema de cooperación para el desarrollo ha descansado hasta el presente muy centralmente en el CAD, un comité especializado de la OCDE, compuesto en la actualidad por 28 donantes bilaterales, además de la UE. Es sintomático que los mismos donantes que defienden el principio de apropiación de las intervenciones de desarrollo por parte de los receptores hayan localizado la gobernanza del sistema de cooperación en una instancia que les pertenece de forma exclusiva" ${ }^{15}$. Añadir que a día de hoy componen el CAD 30 miembros.

El Programa de las Naciones Unidas para el Desarrollo ha sido el mayor promotor de la gobernanza en la cooperación internacional para el desarrollo a nivel global. El concepto de la gobernanza para el PNUD se basa en "qué es lo que hace que las instituciones y reglas sean más efectivas y eficientes, a efectos de lograr la igualdad, transparencia, participación, respuesta, rendición de cuentas y el Estado de derecho"16, siempre desde el parámetro de

14 José Antonio Ocampo (editor) (2015): Gobernanza global y desarrollo. Nuevos desafíos y prioridades de la cooperación internacional. Buenos Aires, Siglo XXI - CEPAL, pp. 65-66.

15 "Más allá de la ayuda. Redefiniendo el sistema de cooperación para el desarrollo", José Antonio Ocampo, Op. cit., p. 196. Ver también Jose Antonio Alonso, José Antonio Ocampo (eds.) (2015): Global Governance and Rules for the Post-2015 Era. Addressing Emerging Issues in the Global Environment, Nueva York, Bloomsbury Academic.

${ }^{16}$ PNUD (mayo 2010): Guía sobre la actividad del PNUD en gobernabilidad democrática, http:// 
la gobernabilidad democrática. Así, la gobernanza engloba el ejercicio de la autoridad política, económica y administrativa en la gestión de los asuntos de un país, en todos los niveles.

¿Qué ámbitos de gobernanza recoge? El PNUD, en la promoción de la gobernanza se guía por cuatro objetivos clave: Prevención de conflictos y consolidación de la paz: promoción de instituciones responsables; procesos políticos inclusivos; y Estado de derecho, justicia y seguridad. Esas opciones encajan con la denominada arquitectura de la cooperación internacional, que se construye sobre varios pilares: el proceso que conduce a la adopción de los Objetivos de Desarrollo del Milenio (2000) y los Objetivos de Desarrollo Sostenible (2015); el proceso para mejorar la ayuda aumentando su calidad, su eficacia, con la Declaración de París sobre la eficacia de la ayuda (2005) y los foros posteriores donde se examina ese proceso; y la financiación del desarrollo, en sus distintas modalidades, desde la Cumbre de Monterrey (2002) hasta la de Addis Abeba (2015).

En el documento aprobado por la Asamblea General de las Naciones Unidas "Transformar nuestro mundo: la Agenda 2030 para el desarrollo sostenible", que hizo suya la cumbre de Naciones Unidas de Nueva York, del 25 al 27 de septiembre de 2015, se reconoce que se contempla "un mundo en que la democracia, la buena gobernanza y el estado de derecho, junto con un entorno nacional e internacional propicio, sean los elementos esenciales del desarrollo sostenible, incluido el crecimiento económico sostenido e inclusivo, el desarrollo social, la protección del medio ambiente y la erradicación de la pobreza y el hambre". Se contrapone a la mala gobernanza, incluida entre los factores que generan violencia, inseguridad e injusticias, como las desigualdades, la corrupción y las corrientes ilícitas de recursos financieros y armas.

Es importante subrayar, en aras de realizar una gobernanza democrática, el proceso participativo que se llevó a cabo en la gestación de los Objetivos de Desarrollo Sostenible, incluyendo la encuesta mundial "Mi mundo" (Toma la palabra. La ONU quiere saber qué es lo que más te importa), que se puede consultar en la página http://vote.myworld2015.org/es/, en la que participaron 1.800.000 personas; en esa encuesta global, la primera prioridad es una buena educación.

Aplicada al caso latinoamericano y en relación a las posibles sinergias entre los procesos de integración regional y la cooperación, "la gobernanza regional de la cooperación se refiere a las articulaciones de los actores regionales orientadas a esos fines (desarrollo económico, social e institucional duradero), tomando a la Cooperación Sur-Sur como una herramienta para su consecución. La gobernanza de la cooperación en la escala regional se ha

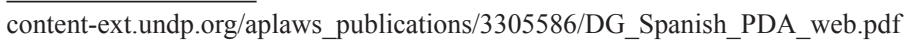


convertido en un asunto de gran importancia en el nuevo contexto planteado a nivel global por la Agenda 2030 para el Desarrollo Sostenible, ya que en el trabajo de implementación de los nuevos Objetivos de Desarrollo Sostenible, los Estados se han comprometido a realizar una labor conjunta entre escalas: global, regional y nacional"17. Entre las críticas a la utilización de una cierta forma de entender la gobernanza en su relación con la cooperación está la que expresa Miguel González Martín en su artículo “¿Ser como Dinamarca? Una revisión de los debates sobre gobernanza y ayuda al desarrollo"18.

\section{La Unión Europea como actor/caso de gobernanza}

El proceso de integración europea que nace con el discurso del ministro francés de Relaciones Exteriores que encabeza este texto, desde ese momento fundacional inspirado por Jean Monnet y basado en el método funcionalista, se basa en la innovación política a escala regional e internacional (supranacionalidad), que supera lo intergubernamental para escalar hacia lo federativo, en cuanto ejercicio de competencias que, transferidas gradualmente por los Estados miembros, son ejercidas conjuntamente por la instituciones de la Unión Europea. Proceso que nace en una Europa devastada por la Segunda Guerra Mundial.

El proceso de integración europea y su encarnación en la UE era una maquinaria de certidumbre, que alcanzó la categoría de alquimia política, según Mark Leonard, para quien la Unión Europea lideraría el siglo XXI. Eran los tiempos en los que Robert Kagan (Poder y debilidad. Europa y Estados Unidos en el nuevo orden mundial, 2003), asociaba a la UE a Venus y EEUU a Marte.

¿Qué tipo de gobernanza aplica la Unión Europea? La Unión Europea explicita su modo de entender la gobernanza por medio del Libro Blanco sobre la gobernanza ${ }^{19}$ : "Con el fin de impulsar una amplia dinámica democrática en la Unión, la Comisión inicia una profunda reforma de la gobernanza y propone cuatro grandes cambios: implicar más a los ciudadanos, definir políticas y legislaciones más eficaces, comprometerse en el debate sobre la gobernanza mundial y, finalmente, centrar las políticas y las instituciones en objetivos claros".

17 Agencia Peruana de Cooperación Internacional (APCI) (2016): La gobernanza de la Cooperación Internacional para el Desarrollo y los procesos de integración y diálogo en América Latina. Documento de Trabajo. Se encuentra en http://www.apci.gob.pe/gestion/atach/La\%20 gobernanza $\% 20 \mathrm{y} \% 20$ procesos\%20de\%20integraci\%C3\%B3n_200716.pdf

18 Hegoa (2007), Working Paper, n. 42, http:/www.ehu.eus/ojs/index.php/hegoa/article/ view/10746/10038

${ }^{19}$ Comunicación de la Comisión, de 25 de julio de 2001, «La gobernanza europea - Un Libro Blanco» [COM (2001) 428 final - Diario Oficial C 287 de 12.10.2001]. 
Una buena gobernanza se basa en cinco principios acumulativos: apertura (las instituciones europeas deben otorgar más importancia a la transparencia y a la comunicación de sus decisiones); participación (conviene implicar de forma más sistemática a los ciudadanos en la elaboración y aplicación de las políticas); responsabilidad (es necesario clarificar el papel de cada uno en el proceso de toma de decisiones para que cada agente concernido asuma la responsabilidad del papel que se le ha atribuido); eficacia (deben tomarse las decisiones a la escala y en el momento apropiados, y éstas deben producir los resultados buscados); coherencia (las políticas que la Unión Europea lleva a cabo son extremadamente diversas y necesitan un esfuerzo continuo de coherencia).

Se propone mejorar el funcionamiento interno de la Unión para, de ese modo, aumentar su presencia en el escenario internacional. Se debe reforzar la presencia de la Unión -siguiendo el objetivo de hablar con una sola voz en el mundo- en, por ejemplo, la Organización Mundial del Comercio y el Tribunal Internacional de Justicia, en ámbitos tales como la gobernanza económica y financiera, el medio ambiente o las políticas de desarrollo y competencia.

Ese Libro Blanco se adopta por la Comisión Europea presidida por Romano Prodi, entre 1999 y 2004, con un modo de gobierno más tecnocrático en sintonía con el auge del neoliberalismo escenificado en el Consenso de Washington, la promoción de los intereses comerciales y la prevalencia del mercado.

En línea con la argumentación anteriormente expuesta,Vidal-Beneyto ${ }^{20}$, parte de que "toda dominación política necesita de una construcción ideológica que justifique su existencia y legitime su ejercicio, y los lenguajes naturales, vehículos necesarios para que ideas y conceptos circulen en el mundo real, son los pilares de esa construcción”; en relación con el Libro Blanco de la Comisión Europea "La gobernanza, pues, denotativamente es la simple acción de gobernar, pero el aura connotativa que le acompaña se encarga de subrayar que esa actividad debe de ejercerse lejos del poder del Estado y cerca del poder de las empresas".

Para hacer frente a ese discurso, hay todo un empeño por parte de diversos representantes de las instituciones europeas, como la Comisaria de Comercio de la UE, Cecilia Malmström ${ }^{21}$ : "Los ciudadanos europeos saben que el comercio puede generar empleo, crecimiento e inversión para los consumidores, para los trabajadores y para las pequeñas empresas. Quieren que haya más resultados en esa línea, pero no a costa de principios fundamentales como los derechos humanos y el desarrollo sostenible en el mundo, o como una legislación y

${ }^{20}$ Ver nota 1, "Gobernabilidad y gobernanza", Tribuna: Las palabras del imperio (I), El País, 12 de abril de 2002.

${ }^{21}$ Comercio para todos: la Comisión Europea presenta la nueva estrategia de comercio e inversión. Bruselas, 14 de octubre de 2015. http://europa.eu/rapid/press-release_IP-15-5806_es.htm 
unos servicios públicos de calidad en sus países. Y quieren saber más sobre las negociaciones que se llevan a cabo en su nombre".

La opción por mantener esa dualidad entre el mercado y la sociedad -la economía social de mercado- figura también en el preámbulo del Tratado de la Unión, donde los Estados miembros se muestran "Decididos a promover el progreso social y económico de sus pueblos teniendo en cuenta el principio de desarrollo sostenible, dentro de la realización del mercado interior y del fortalecimiento de la cohesión y de la protección del medio ambiente, y a desarrollar políticas que garanticen que los avances en la integración económica vayan acompañados de progresos paralelos en otros ámbitos".

La relación entre Estado, mercado y sociedad en distintos esquemas regionales ha sido tratada por Francisco Aldecoa y Noé Cornago ${ }^{22}$, explicitando las características del modelo europeo. Uno de los casos en los que se ha aplicado esa gestión conjunta en un área de actividad es la relativa a la gobernanza internacional de los océanos: una agenda para el futuro de nuestros océanos $^{23}$. Desde otra perspectiva, se critica habitualmente a la Unión por no haber establecido una mayor gobernanza en la unión económica y monetaria, alejándola de los procesos de participación y control democráticos.

\section{La Unión Europea como actor global y su papel en la gobernanza}

La Unión Europea se ha caracterizado como potencia normativa y como potencia civil; la UE no sólo quiere ser un actor global, sino que tiene el mandato, según el artículo 21.2.h del Tratado de la Unión Europea, de "promover un sistema internacional basado en una cooperación multilateral sólida y en una buena gobernanza mundial" ${ }^{24}$. La Declaración de Laeken sobre el futuro de la Unión Europea ${ }^{25}$, de 15 de diciembre de 2001, se preguntaba ¿cuál es el papel de Europa en este mundo transformado?, para plantearse ¿no debería Europa, ahora por fin unificada, desempeñar un papel de liderazgo en un nuevo orden planetario, el de una potencia a la vez capaz de desempeñar

${ }^{22}$ Francisco Aldecoa y Noé Cornago (1998): "El nuevo regionalismo y reestructuración del sistema mundial”, Revista Española de Derecho Internacional, vol. L, n. 1, pp. 59-113.

23 Comunicación para establecer medidas para garantizar unos océanos seguros, limpios y gestionados de manera sostenible. Bruselas, 10 de noviembre de 2016, JOIN/2016/049 final.

${ }^{24}$ En la obra dirigida por Esther Barbé, La Unión Europea en las relaciones internacionales (Madrid, Tecnos, 2014), la tercera parte de la obra se dedica a "Actor en la gobernanza global": "Los capítulos de este apartado se sitúan en la convergencia entre una UE con voluntad manifiesta de liderar la gobernanza y un sistema internacional en proceso de transición, con la emergencia de nuevas potencias y la agudización del proceso de globalización. De ahí que el análisis que todos ellos realizan en torno a procesos, mecanismos e instrumentos de la UE, como la representación o la coordinación en los foros multilaterales, ofrezca conclusiones en términos de evaluación sobre la influencia y, por tanto, sobre la capacidad de la UE por ejercer el rol de líder en la gobernanza global”, p. 31.

${ }^{25}$ Ver http://european-convention.europa.eu/pdf/lknes.pdf 
una función estabilizadora a nivel mundial y de ser punto de referencia para numerosos países y pueblos? La respuesta que los Gobiernos de los países miembros dan, de forma consensuada es que "El papel que debe desempeñar es el de una potencia que lucha decididamente contra cualquier violencia, terror y fanatismo, pero que tampoco cierra los ojos ante las injusticias flagrantes que existen en el mundo. En resumen, una potencia que quiere hacer evolucionar las relaciones en el mundo de manera que no sólo beneficien a los países ricos sino también a los más pobres. Una potencia que quiere enmarcar éticamente la mundialización, es decir, ligarla a la solidaridad y al desarrollo sostenible". Por formulaciones como la anterior, se crítica a la Unión Europea por su 'buenismo', haciendo referencia a su tradicional idealismo.

En el Tratado de la Unión, firmado en Lisboa el 13 de diciembre de 2007 y que entró en vigor el 1 de diciembre de 2009, los Estados miembros se muestran "resueltos a desarrollar una política exterior y de seguridad común que incluya la definición progresiva de una política de defensa común que podría conducir a una defensa común de acuerdo con las disposiciones del artículo 17, reforzando así la identidad y la independencia europeas con el fin de fomentar la paz, la seguridad y el progreso en Europa y en el mundo". Más allá de que la semántica tiene en ésta una frase digna de considerar como estudio, muestra la ambición europea por reforzar una dimensión especial de su proceso de integración, pero también los límites subyacentes a que ese proceso está condicionado, en última instancia, a la aprobación por los propios Estados miembros.

La historia de la integración europea nos recuerda el fracaso de la Comunidad Europea de Defensa, Tratado adoptado el 27 de mayo de 1952, que nunca llegó a entrar en vigor -tras la negativa de la Asamblea nacional de Francia-, en cuyo artículo 1 se establecía que "Por el presente Tratado, las Altas Partes Contratantes instituyen entre ellas una Comunidad Europea de Defensa, de carácter supranacional, que posea instituciones, Fuerzas Armas y presupuesto común".

El Tratado de Lisboa refuerza la política y las instituciones para que la Unión se convierta en un actor global ${ }^{26}$, pero el Tratado se va a aplicar en un contexto de grave crisis económica, de grave crisis política (cuestionamiento interno, tensiones entre Gobiernos y la propia Unión, el 'Brexit'...) y un entorno internacional desfavorable.

${ }^{26}$ Ver la obra dirigida por Esther Barbé, Cambio mundial y gobernanza global. La interacción entre la Unión Europea y las instituciones internacionales (Madrid, Tecnos, 2012), en la que se tratan los siguientes temas que nos permiten comprender la amplitud de ámbitos donde está presente la UE como actor internacional: la representación exterior de la UE; las relaciones con las potencias emergentes; el reconocimiento social en los marcos multilaterales; la UE en el ámbito agrícola; la UE ante el Tratado de No Proliferación Nuclear; la política internacional del clima; la UE y el Estatuto de Roma; la UE y la política energética; la UE y la lucha contra la delincuencia organizada transnacional; la UE y el régimen internacional de diamantes. 
La Política Exterior y de Seguridad de la $\mathrm{UE}^{27}$, que lleva muchos años desarrollándose, le permite expresarse y actuar con personalidad propia en la escena internacional. Actuando conjuntamente, los 28 países de la UE tienen más fuerza que si lo hicieran por separado. El Tratado de Lisboa, de 2009, fortaleció la política exterior de la UE al crear el cargo de Alto Representante de la UE para Asuntos Exteriores y Política de Seguridad -cargo que ocupa Federica Mogherini-, el Servicio Europeo de Acción Exterior (SEAE) como cuerpo diplomático de la UE. La misión de la Política Exterior y de Seguridad de la UE es mantener la paz y afianzar la seguridad internacional, fomentar la cooperación internacional, desarrollar y consolidar la democracia, el Estado de Derecho y el respeto de los derechos humanos y las libertades fundamentales.

Estamos ante lo que, en línea con la mencionada Declaración de Laeken, Francisco Aldecoa y Mercedes Guinea definen como política de responsabilidad: "la acción exterior se define en base a una política de responsabilidad, esto es, sobre la necesaria implicación europea en la gestión de los problemas internacionales"28.

La opción europea por hablar con una sola voz en el escenario internacional y promover el multilateralismo eficaz choca contra varios obstáculos. Uno, quizá el principal, es la dificultad para armonizar la voz de las instituciones europeas con las de 28 Estados miembros - por lo menos hasta la salida de Gran Bretaña-, en lo que se conoce como la cacofonía europea ${ }^{29}$. Así lo reflejan, por ejemplo, las distintas posiciones de los Estados miembros en torno a la votación de cuestiones problemáticas en las Naciones Unidas, como en el caso de Palestina cuando la Asamblea General trató su estatus como observador, el 28 de noviembre de 2012: 138 votos a favor (entre ellos España, Francia, Italia o Portugal), 9 en contra (entre ellos la República Checa) y 41 abstenciones (entre ellos Alemania y el Reino Unido).

Este Objeto Político No Identificado, como lo definió Jacques Delors, quien fue presidente de la Comisión Europea entre 1985 y 1995, no encaja fácilmente en un sistema interestatal, aunque haya conseguido, en función de las competencias que tiene atribuidas, ocupar asiento propio en la FAO, en la $\mathrm{OMC}$, en el G20 o en el CAD. La tensión entre una forma supranacional y lo intergubernamental está en el fondo de los problemas para que la Unión fuera admitida como observador en la ONU, lo que no logró, tras varios intentos fallidos, hasta el 3 de mayo de 2011, en la que se aprueba su incorporación con el estatuto de observador no estatal sin ningún voto en contra y con las abstenciones de Siria y Zimbabue ${ }^{30}$. Además, la acentuada crisis que sufre la

\footnotetext{
${ }_{27}$ Tomado de https://europa.eu/european-union/topics/foreign-security-policy_es

28 Francisco Aldecoa y Mercedes Guinea (2010): La Europa que viene: El Tratado de Lisboa, Madrid, Marcial Pons, p. 213.

29 José Ignacio Torreblanca (2011): La fragmentación del poder europeo, Barcelona, Icaria.

${ }^{30}$ Ese caso se trata en la obra de Esther Barbé citada en la nota 22, pp. 23-24. Ver también el texto
} 
Unión ha disminuido su capacidad de actuar internacionalmente, le ha hecho perder credibilidad y, aunque tenga la potencialidad establecida por sus normas para tener mayor presencia global, es cierto que su protagonismo internacional se ve ensombrecido por la pujanza de otros actores.

Por todo ello, la Unión trata de hacer frente a esas carencias y debilidades reforzando su proyección exterior, que se ve crecientemente debilitada ${ }^{31}$. Ese es el objetivo de la Estrategia Global de la Unión Europea ${ }^{32}$, documento que se asiente en los valores de la Unión y en el que se establecen cinco prioridades: la seguridad de la Unión; resiliencia estatal y nacional de los vecinos orientales y meridionales; un enfoque integrado de conflictos; órdenes regionales de cooperación; y gobernanza mundial para el siglo XXI. Para lograrlo, la Unión deberá hacer frente a una serie de incoherencias que lastran sus propósitos. Entre los ámbitos en los que se observa ese desequilibrio entre lo que propone y lo que lleva a cabo está el de los derechos humanos ${ }^{33}$.

También se observan esas incoherencias en el caso de su papel en el desarrollo humano; para Natalia Millán ${ }^{34}$, "más allá de los indiscutibles avances de la UE en el plano discursivo, el trabajo en la promoción del desarrollo debe ser valorado en función de las acciones reales que desarrollen los estados e instituciones, así como las consecuencias de la implementación de estas políticas para los derechos humanos de la ciudadanía cosmopolita. En este sentido, las políticas europeas desarrolladas en el último lustro no solo han tenido consecuencias profundamente negativas para otros países y personas, sino que han precarizado de manera muy significativa las condiciones de vida

de Sergio Salinas Alcega, "La acción de la Unión Europea en la Asamblea General de las Naciones Unidas: un test de su condición de actor global en materia de derechos humanos", en la obra de Antonio Blanc Altemir (2013): Las relaciones entre las Naciones Unidas y la Unión Europea. Seguridad, cooperación y derechos humanos, Madrid, Tecnos, pp. 436-463. También Luis N. González Alonso (director), Asier Garrido Muñoz (coordinador) (2011): La Unión Europea y el multilateralismo eficaz ¿Un compromiso consistente con Naciones Unidas?, Madrid, Iustel.

${ }^{31}$ Joseph S. Nye, autor de Is the American Century Over?, en el artículo "El peligro de una Europa débil", plantea que "la pregunta clave es si la UE conservará la cohesión suficiente para hablar con una sola voz en asuntos internacionales o seguirá siendo una agrupación limitada y definida por las identidades nacionales. A EEUU le interesa un aliado sólido", ver http://elpais.com/elpais/2016/02/15/ opinion/1455560331_356222.html

32 "La visión común, acciones comunes: Una Europa más fuerte - una estrategia global de la Unión Europea para la política exterior y de seguridad", Alto Representante de la Unión para Asuntos Exteriores y Política de Seguridad de junio de 2016. El Consejo de la UE establece sus conclusiones sobre este documento en su reunión de 17 de octubre de 2016, ver http://www.consilium.europa.eu/ es/press/press-releases/2016/10/17-fac-eu-global-strategy/

${ }_{33}$ Entre los múltiples casos, están las críticas que John G. Ruggie -antiguo Representante Especial del Secretario General de las Naciones Unidas para las Empresas y los Derechos Humanos y autor de los Principios Rectores de las Naciones Unidas sobre Empresas y Derechos Humanos- realiza con respecto al papel de las empresas y los derechos humanos en el ámbito de la UE, tal como señala en la carta enviada al Presidente de la Comisión Europea el 24 de febrero de 2017.

34 "El papel "dual" de la Unión Europea en la promoción del desarrollo humano", en Anuario 2013. Hacia 2015: Visiones del desarrollo en disputa, XI Informe Anual de la Plataforma 2015 y más, 2014, http://2015ymas.org/centro-de-documentacion/publicaciones/2014/1573/\#.WM-wnG_hCUl 
de una parte importante de la población que vive en Europa. Por tanto, parece existir una brecha más que significativa entre los compromisos políticos en Coherencia de Políticas de Desarrollo (CPD) asumidos por las instituciones comunitarias y los Estados miembros y las acciones reales encaminadas a promover una mayor CPD en ambos niveles (comunitario y nacional)". Yendo un paso más allá, se ha observado la contradicción entre ese modelo de desarrollo sostenible que prioriza el mercado y la integración económica. Incluso se cuestiona la compatibilidad de ese modelo de desarrollo sostenible, al ser sus términos contradictorios ${ }^{35}$.

\section{La gobernanza europea del desarrollo}

La gradual incorporación de la política de desarrollo al ámbito de competencias de la Unión Europea no se puede explicar sin contar con el pasado colonial de una buena parte de los Estados que conforman ese proceso de integración, especialmente Francia. La relación postcolonial se traslada a la Europa comunitaria mediante la vinculación con los países y territorios de ultramar, base para la relación con los países de África, Caribe y Pacífico (ACP) que conforman el Acuerdo de Cotonú (20 de junio de 2000), entre la Unión Europea y 78 países de esas tres regiones ${ }^{36}$.

Será el Tratado de la Unión Europea de Maastricht (firmado el 7 de febrero de 1992, entró en vigor el 1 de noviembre de 1993) el que incorpora formalmente a la Comunidad Europea la política de cooperación para el desarrollo. Aunque la UE sea un actor sui generis, en el caso de la política de cooperación se aplica el mismo criterio que para otros actores: es parte de su política exterior. Pero dado que la política de cooperación como parte de la política exterior afecta al núcleo duro de la soberanía estatal, los Estados son más reacios a esta transacción, con lo cual se busca una fórmula para que la política europea conviva con las políticas nacionales de cooperación. De

\footnotetext{
35 José Ángel Sotillo Lorenzo (2017): Desarrollo económico y sostenibilidad medioambiental: contribuciones de la Unión Europea a la definición de un orden internacional acorde a las necesidades del siglo XXI. Obra colectiva España y la Unión Europea en el orden internacional. Valencia, Tirant lo Blanch y Universidad de Sevilla, 2017, pp. 1225-1251. "El síntoma se llama calentamiento climático, pero la enfermedad se llama capitalismo", proclama Jorge Reichmann (2015) en Autoconstrucción. La transformación cultural que necesitamos, Madrid, Los Libros de la Catarata. En relación a su repercusión en el ordenamiento jurídico internacional, Antonio Cardesa-Salzmann y Antoni Pigrau Solé, "La Agenda 2030 y los Objetivos para el Desarrollo Sostenible. Una mirada crítica sobre su aportación a la gobernanza global en términos de justicia distributiva y sostenibilidad ambiental", Revista Española de Derecho Internacional, vol. 69 (2017), I, pp. 279-285.

36 José Ángel Sotillo Lorenzo y Javier Leonardo Surasky (2016): "Las relaciones entre Europa y América Latina en perspectiva decolonial ¿Encuentro o desencuentro?”, Iberoamérica Social: revista-red de estudios sociales, VI, pp. 54 - 68. Recuperado en http:// iberoamericasocial.com/ lasrelaciones-europa-america-latina-perspectiva-decolonial-encuentro-desencuentro.
} 
este modo la política europea de cooperación será complementaria a la de los Estados miembros.

Así queda recogido en el artículo 4 del Tratado de Funcionamiento de la UE (TFUE), artículo 4.4.: "En los ámbitos de la cooperación para el desarrollo y la ayuda humanitaria, la Unión dispondrá de competencia para llevar a cabo acciones y una política común, sin que el ejercicio de esta competencia pueda tener por efecto impedir a los Estados ejercer la suya".

Para mejorar el trabajo conjunto de las distintas políticas de cooperación europeas -las de los Estados miembros y la de la propia Unión- se establecen medidas relativas a la coherencia, coordinación y complementariedad: "La Unión tendrá en cuenta los objetivos de la cooperación para el desarrollo al aplicar las políticas que puedan afectar a los países en desarrollo" (artículo 208.1 del TFUE); "Con el objetivo de favorecer la complementariedad y la eficacia de sus acciones, la Unión y los Estados miembros coordinarán sus políticas en materia de cooperación al desarrollo y concertarán sus programas de ayuda, también en el marco de organizaciones internacionales y de conferencias internacionales. Podrán emprender acciones conjuntas. Los Estados miembros contribuirán, si fuere necesario, a la ejecución de los programas de ayuda de la Unión" (artículo 210.1 del TFUE).

Según el Tratado, la Unión tiene el mandato de, "En sus relaciones con el resto del mundo, la Unión afirmará y promoverá sus valores e intereses y contribuirá a la protección de sus ciudadanos. Contribuirá a la paz, la seguridad, el desarrollo sostenible del planeta, la solidaridad y el respeto mutuo entre los pueblos, el comercio libre y justo, la erradicación de la pobreza y la protección de los derechos humanos, especialmente los derechos del niño, así como al estricto respecto y al desarrollo del Derecho Internacional, en particular el respeto de los principios de la Carta de las Naciones Unidas" (artículo 3.5 TUE).

Al tratar las disposiciones generales relativas a la acción exterior de la Unión se establece, entre otras medidas, la de "apoyar el desarrollo sostenible en los planos económico, social y medioambiental de los países en desarrollo, con el objetivo fundamental de erradicar la pobreza" (artículo 21.2.d del TUE); y "contribuir a elaborar medidas internacionales de protección y mejora de la calidad del medio ambiente y de la gestión sostenible de los recursos naturales mundiales, para lograr el desarrollo sostenible (artículo 21.2.f).

Junto a lo establecido por los Tratados, la política europea de cooperación ha ido evolucionando especialmente desde la adopción por el Parlamento Europeo, la Comisión y el Consejo, el 20 de diciembre de 2005, del Consenso Europeo sobre Desarrollo, un texto alineado con los Objetivos de Desarrollo del Milenio. En él se potencia el papel de la Unión como actor de la gobernanza. En ese sentido, se considera también que el objetivo fundamental de reducción 
de la pobreza abarca los objetivos complementarios como el fomento de la buena gobernanza y el respeto de los derechos humanos, valores comunes que constituyen los cimientos de la UE. La lucha contra la pobreza implica también alcanzar un equilibrio entre las actividades vinculadas al desarrollo humano, la protección de los recursos naturales y el crecimiento económico, y la creación de riqueza en favor de las poblaciones pobres. Uno de los ámbitos donde la Unión centrará su actividad será gobernanza, democracia, derechos humanos y apoyo a las reformas económicas e institucionales.

El Consejo Europeo, en su reunión de 26 y 27 de junio de 2014, adoptaba la orientación política de la Unión, “Asociación estratégica para la Unión en tiempos de cambio" ${ }^{37}$, estableciendo sus prioridades: una Unión de empleo, crecimiento y competitividad; una Unión que capacita y protege a todos los ciudadanos; hacia una Unión de la Energía con una política climática dotada de perspectiva de futuro; una Unión de libertad, seguridad y justicia; la Unión como actor fuerte a nivel mundial.

En una agenda que se alineará con los Objetivos de Desarrollo Sostenible, se lleva a cabo la adopción de un nuevo consenso europeo sobre el desarrollo. Asumiendo su papel de promotor de iniciativas, la Comisión Europea plantea, el 22 de noviembre de 2016, las prioridades políticas para la aplicación de la Agenda 2030 que, para el Comisario de Cooperación Internacional y Desarrollo, Neven Mimica ${ }^{38}$ son las de "liderar la acción mundial en pos de la aplicación de los Objetivos de Desarrollo Sostenible... confirmar de forma inequívoca la voluntad de la UE de trabajar con nuestros socios de todo el mundo para construir un mejor futuro para todos, un alto nivel de desarrollo económico, cohesión social, sociedades democráticas y un compromiso con el desarrollo sostenible".

En ese sentido, la "Propuesta para Nuevo Consenso Europeo en materia de Desarrollo. Nuestro Mundo, nuestra Dignidad, nuestro Futuro"39 propone todo un despliegue para una mejor gobernanza, buena gobernanza, gobernanza democrática, gobernanza eficaz y gobernanza integradora; en concreto, en el punto 73: "La UE y sus Estados miembros colaborarán con las organizaciones multilaterales, y en particular con el sistema de las Naciones Unidas, el Fondo Monetario Internacional (FMI), el Grupo del Banco Mundial, el G7, el G20, la OCDE y otras instituciones multilaterales, para que se unan a la Agenda 2030 y fomenten la ayuda mutua en el marco de su aplicación. La UE y sus Estados miembros buscarán sinergias con las Naciones Unidas, tanto a escala mundial

\footnotetext{
${ }^{37}$ Ver el documento en http://data.consilium.europa.eu/doc/document/ST-79-2014-INIT/es/pdf

38 "Desarrollo sostenible: La UE anuncia sus prioridades", Estrasburgo, 22 de noviembre de 2016 http://europa.eu/rapid/press-release_IP-16-3883_es.htm

${ }^{39}$ Comunicación de la Comisión al Parlamento Europeo, al Consejo, al Comité Económico y Social Europeo y al Comité de las Regiones: "Propuesta para Nuevo Consenso Europeo en materia de Desarrollo. Nuestro Mundo, nuestra Dignidad, nuestro Futuro". COM (740) final, Estrasburgo, 22.11.2016
} 
como con los equipos nacionales de las Naciones Unidas sobre el terreno, con el objetivo, entre otros, de mejorar la eficacia de la ONU. Se alentará a los países en desarrollo a participar en la gobernanza de las organizaciones multilaterales".

Las propuestas de la Comisión se completan con la Comunicación "Próximas etapas para un futuro europeo sostenible Acción europea para la sostenibilidad" ${ }^{\prime \prime}$, en la que se explicita la manera en que la UE llevará adelante la aplicación de la agenda 2030: "3.1. Gobernanza: El desarrollo sostenible requiere un enfoque político global e intersectorial para asegurarse de que los retos económicos, sociales y medioambientales se abordan conjuntamente. Por ello, en última instancia el desarrollo sostenible es una cuestión de gobernanza que requiere los instrumentos adecuados para garantizar la coherencia política en las diversas áreas temáticas, así como entre la acción exterior de la UE y sus demás políticas". Para hacer operativa la propuesta de la Comisión Europea, la compleja maquinaria europea lleva a que esa propuesta se debata en el Consejo de Asuntos Exteriores de la UE, el Parlamento Europeo debata y apruebe un informe, el Comisario de Cooperación Internacional y Desarrollo se reúna con Gobiernos y Parlamentos de Estados miembros y, finalmente la propuesta de la Comisión sea consensuada con el Consejo y el Parlamento Europeo, como sucedió con la adoptada en 2005.

En ese proceso es importante subrayar que la Unión establece formas para la participación ciudadana por medio de la consulta pública en línea, junto a la realización de debates en foros y mecanismos consultivos, así como en trabajos preparatorios de evaluación ${ }^{41}$. A pesar de estos avances, desde la sociedad civil se sigue exigiendo a la Unión que sea más efectiva a la hora de llevar a la práctica sus propuestas ${ }^{42}$, de que no tenga solo un discurso benevolente y una voluntad política, sino trasladarlas a la realidad.

${ }^{40}$ Comunicación de la Comisión al Parlamento Europeo, al Consejo, al Comité Económico y Social Europeo y al Comité de las Regiones: Próximas etapas para un futuro europeo sostenible Acción europea para la sostenibilidad. COM (739) final, Estrasburgo, 22.11.2016

${ }^{41}$ Ver Comisión Europea "Synopsis Report summarising the main results of the consultation on the new European Consensus on Development", Estrasburgo, 22.11.2016, SWD(2016) 389 final; y "Assessing the 2005 European Consensus on Development and accompanying the initiative "Proposal for a new European Consensus on Development", Estrasburgo, 22.11.2016, SWD(2016) 387 final

42 "Now actions must speak louder than words", es lo que reclaman las ONG europeas en respuesta a las iniciativas de la Comisión Europea; ver Helene Debaisieux, de CONCORDE -que representa a 2600 ONG europeas- : "European governments need to stand up for a new approach that promotes sustainable development globally as the best response to the challenges facing our continent and the world", 22 noviembre 2016, en https://concordeurope.org/2016/11/22/ec-packagereaction-new-consensus/. Por su parte SDG Watch Europe expresa su decepción tras la publicación por la Comunicación de la Comisión Europea sobre los próximos pasos para un futuro europeo sostenible: la acción europea para la sostenibilidad; ver el comunicado de prensa de 23 de noviembre de 2016 en https://www.sdgwatcheurope.org/single-post/2016/11/23/Statement-on-the-EuropeanCommission $\%$ E2\%80\%99s-Communication-on-European-action-for-sustainability 


\section{Unión Europea: ¿policrisis o crisis de modelo?}

En consonancia con los retos y desafíos anteriores, ¿está la Unión Europea en condiciones de ser un actor clave en la gobernanza global cuando está en cuestionamiento su propia existencia?

Por primera vez su historia, el mantra que se aplicaba en base a la idea de Jean Monnet de que la construcción europea será forjada en las crisis, corre el riesgo de perder sentido, si hacemos caso a quienes quieren acabar con ese modelo de Europa unida, en lo que se califica como una crisis existencial. Buena parte de los indicadores económicos o sociales indican la pérdida de peso e influencia de la Unión en el mundo que se avecina. En el campo demográfico, si en la actualidad representa el 7\% de la población mundial, en 2060 representará menos del 5\% con una de las poblaciones más envejecidas del planeta.

En un clima de deterioro, la conjunción de una serie de elementos viene a provocar una especie de tormenta perfecta que pone en cuestión a la propia Unión Europa. Es una crisis global, tanto en su dimensión interna (crisis económica: ajuste, recesión ('rescates'), pérdida de credibilidad; 'Brexit' y posible nuevo referéndum en Escocia, parálisis y falta de reacción ante los graves problemas que sufre, ausencia de liderazgo europeo...), como externa (pérdida de peso e influencia, escasa credibilidad, ausencia de protagonismo...). Una de las palabras que mejor refleja la situación es 'austericidio', situación en la que por vez primera desde la creación de una Europa unida, las generaciones actuales viven peor que las anteriores; además, expresiones que se utilizaban para otras partes del mundo, recorren buena parte del territorio europeo: aumento de la pobreza y, especialmente, de la desigualdad, y se hace más evidente en grupos de población más vulnerables, como la infancia.

En ese clima de pesimismo, la UE ha sido declarada enemigo por los partidos y movimientos más reaccionarios, xenófobos, proteccionistas, nacionalistas... Casi solo por ese hecho debería contar con más apoyos de los que últimamente tiene. En el estado en que se encuentra la Unión Europea convendría cambiar el himno europeo, el himno de la alegría -'Oda a la alegría', de Friedrich von Schiller que Beethoven trasladó a la novena sinfonía-, por el himno de la tristeza. Una situación que también es reflejo de la pérdida de profundidad en la construcción de una democracia europea; aún más, parte del discurso gira en torno a la gobernanza antidemocrática en la Unión Europea ${ }^{43}$.

\footnotetext{
43 Para el periodista Leigh Phillips ,"Estamos viviendo en la era de la construcción de una arquitectura de gobernanza global pero exenta de una democracia global"; Phillips concluye que los Estados europeos están enredados en estructuras internacionales de gobernanza y pierden así su soberanía, mientras los mercados globales no se dejan ni aconsejar ni supervisar". Es la columna vertebral de El orden global postdemocrático, incluido en el informe El Estado Del Poder 2016, ver http:/www.lamarea.com/2016/02/15/81938/
} 
Para Boaventura de Sousa Santos, "un sentimiento de agotamiento histórico y político recorre Europa y el norte global en general. Tras cinco siglos de imponer soluciones al mundo, Europa parece incapaz de resolver sus propios problemas, y entrega su resolución a empresas multinacionales a través de acuerdos de libre comercio, cuyo objetivo es eliminar los últimos resquicios de cohesión social y de conciencia ambiental adquiridos después de la Segunda Guerra Mundial" 44 . En el informe editado por Regina A. List, The Governance Report 2015: European Union governance, con contribuciones de Mark Dawson, Henrik Enderlein, Christian Joerges, Liam F. McGrath ${ }^{45}$, se plantea incluso si la Unión Europea puede mantener su papel de modelo político.

\section{Opciones de salida a la crisis: mayor y mejor gobernanza}

Una vez más, la salida de la crisis está en manos de los Gobiernos de los Estados miembros y, especialmente, de aquellos que tienen una responsabilidad mayor. Pero se ciernen toda clase de dudas sobre el futuro de una Europa unida, sobre el propio modelo de integración europea que, por vez primera, corre el riesgo de retroceder en lugar de avanzar. Entre las múltiples sombras que acechan al esquema de integración, algunas ya comentadas, encontramos la salida de Gran Bretaña y sus importantísimos efectos; la incertidumbre de la agenda política con elecciones en Holanda, Francia y Alemania (y, en el horizonte, las elecciones al Parlamento Europeo en 2019); la ralentización de la ampliación, muy complicada en el caso de Turquía; el auge de la xenofobia que tienen como bandera partidos de extrema derecha que han declarado a la Unión como una especie a extinguir. A lo anterior hay que añadir las turbulencias mundiales desatadas tras la llegada a la Casa Blanca de Donald Trump; en el caso que nos ocupa la primera señal que ha emitido fue recibir al político inglés Nigel Farage, del Partido de la Independencia del Reino Unido. La nueva política exterior de Estados Unidos lleva a la parálisis las negociaciones para el ya muy criticado Tratado Transatlántico de Comercio e Inversiones (Transatlantic Trade and Investment Partnership TTIP, por sus siglas en inglés).

$\mathrm{Y}$, sin duda alguna, si algo debe avergonzar a toda Europa es el tratamiento dado a las personas que huyen de la violencia y del conflicto; aunque haya una tímida política migratoria con fondos europeos gestionados por medio de una red de actores y se lleven a cabo acciones para canalizar recursos de modo que Gobiernos de países emisores tengan políticas activas para el retorno o frenar la emigración, la respuesta europea deja de lado los principios humanitarios e

44 "Europa debe regresar a la escuela del mundo, como alumna", artículo publicado el 3 de marzo de 2017, ver http://www.alainet.org/es/articulo/183887

45 Ver un resumen ejecutivo en http://www.governancereport.org/home/2015/ 
incluso el derecho internacional para intentar frenar la llegada de inmigrantes, bien con un raquítico reparto de cupos que, además, es incumplido (por ejemplo por España) o llegando a acuerdos para que otros países sirvan de tapón o de muro, como en caso de Turquía. Es la Europa fortaleza frente a la Europa socio, que tiene como consecuencia situaciones dramáticas especialmente para los niños refugiados y migrantes, como reflejan los informes periódicos de Unicef o Save the Children. Por otro lado, también se ha dicho que la Europa unida goza de una mala salud de hierro y que la máquina europea avanza a pesar de todas las dificultades; recordemos que la Unión tiene aprobadas sus perspectivas financieras plurianuales para el período 2014-2020.

Cuestionado el liderazgo europeo y el tradicional eje París-Berlín, la responsabilidad compartida para avanzar le corresponde a los países con mayor peso. De ahí la reunión -la conocida como cumbre de Versalles-, el 6 de marzo de 2017, en la que los representantes de Alemania (Angela Merkel), España (Mariano Rajoy), Francia (François Hollande) e Italia (Paolo Gentiloni) inician el proceso de reflexión sobre el rumbo que debe tomar el proyecto europeo sin el Reino Unido, con la opción de la Europa unida, pero a varias velocidades (lo que ya contempla el Tratado con las cooperaciones reforzadas ${ }^{46}$.

Esa opción es uno de los cinco escenarios que contempla el "Libro Blanco sobre el futuro de Europa. Reflexiones y escenarios para la Europa de los Veintisiete en $2025^{\prime \prime 4}$, presentado el 1 de marzo de 2017 por el presidente de la Comisión Europea, Jean Claude Juncker. Los cinco escenarios para Europa en 2025 son: seguir igual; solo el mercado único; los que desean hacer más, hacen más; hacer menos pero de forma más eficiente; hacer mucho más conjuntamente.

${ }^{46}$ Según establece el artículo 20 del Tratado de la UE "Los Estados miembros que deseen instaurar entre sí una cooperación reforzadas en el marco de las competencias no exclusivas de la Unión podrán hacer uso de las instituciones de ésta y ejercer dichas competencias aplicando las disposiciones pertinentes de los Tratados, dentro de los límites y con arreglo a las modalidades contempladas en el presente artículo y en los artículos 326 a 334 del Tratado de Funcionamiento de la Unión Europea. La finalidad de las cooperaciones reforzadas será impulsar los objetivos de la Unión, proteger sus intereses y reforzar su proceso de integración. Las cooperaciones reforzadas estarán abiertas permanentemente a todos los Estados miembros, de conformidad con el artículo 328 del Tratado de Funcionamiento de la Unión Europea". La cooperación reforzada es un procedimiento que permite que un mínimo de nueve países de la UE establezcan una integración o cooperación avanzada en un ámbito de las estructuras europeas sin la participación de los demás países de la UE. De este modo, pueden progresar según ritmos u objetivos diferentes a los establecidos para aquellos que no participan en la cooperación reforzada. Este procedimiento está diseñado para superar la parálisis, cuando una propuesta es bloqueada por un único país o por un pequeño grupo de países que no desean participar en la iniciativa. Sin embargo, no permite una ampliación de las competencias más allá de las recogidas en los tratados europeos.

La autorización para proceder con la cooperación reforzada la concede el Consejo, a propuesta de la Comisión y después de obtener el consentimiento del Parlamento Europeo.

Desde febrero de 2013, este procedimiento se está utilizando en los ámbitos de la ley aplicable al divorcio y las patentes, además de estar aprobado para el ámbito de un impuesto sobre las transacciones financieras. http://eur-lex.europa.eu/summary/glossary/enhanced_cooperation.html?locale=es

47 Ver el documento en https://ec.europa.eu/commission/white-paper-future-europe-reflectionsand-scenarios-eu27-2025_es 
La opción hacia la que se tiende es la de que los que desean hacer más, hagan más -en línea con las cooperaciones reforzadas antes mencionadas-, recuperando un método que, aplicado a un proceso de integración cada vez más numeroso, con más riesgo de dispersión por su gran heterogeneidad, pero que sigue perteneciendo a la Unión Europea, permite avanzar sin que quienes no quieren o no pueden, veten esos avances. Los nombres con los que se identifica ese método de trabajo que permiten modular dentro de la Unión los avances en el proceso de integración son variados: Europa a la carta, de distintas velocidades, de geometría variable, de círculos concéntricos. El riesgo es que se cree una especie de subagrupaciones regionales o que el peso de los Estados (de los más poderosos) sea quien tenga mucho más peso en la balanza que las instituciones de la Unión Europea. Curiosamente, la Unión se ve en cierta medida dividida por varias 'frontera': países del Norte contra los del Sur/periferia (identificados hace unos años como los PIGS por su acrónimo en inglés: Portugal, Irlanda, Grecia y España) y los del Oeste contra los del Este. Tras ser reelegido el 9 de marzo de 2017 como Presidente del Consejo Europeo, con la oposición del Gobierno de su país, el polaco Donald Tusk, advertía del riesgo de un nuevo telón de acero y reclamaba la toma de posiciones para el futuro de Europa de la mano de un proverbio africano: "si quieres ir rápido, ve solo; si quieres ir más lejos, vamos juntos".

Un caso de aplicación de ese método es el de la propuesta de tasa de transacciones financieras ${ }^{48}$ (la denominada tasa Tobin o tasa Robin Hood), cooperación reforzada en la que participan Alemania, Austria, Bélgica, Eslovaquia, Eslovenia, Francia, Grecia, Italia, España y, Portugal.

En todo el proceso de integración europea ha existido esa tensión entre quienes defienden un modelo que mantenga un mayor peso y control por parte de los Estados y quienes propugnan un modelo de corte federal. Es la 'batalla' entre los arquitectónicos -avanzar, pero combinando lo supranacional con lo intergubernamental- y los botánicos -un árbol que simbolizara unas raíces y un tronco común- con que se identificó las opciones con respecto al Tratado de la Unión Europea de Maastricht. En todo caso, queda claro que, junto a la ausencia de liderazgo europeo, las reuniones periódicas de gobernantes de la Unión parecen confirmar el dicho de que cuando los líderes no saben qué hacer, convocan una cumbre. Quizá por eso, frente al creciente desánimo que capitaliza la ultraderecha antieuropea, se alzan voces como las de "Pulse of Europe", un movimiento ciudadano que promueve una Europa fuerte y eficaz.

Las lecciones del pasado demuestran que el proceso de integración europea ha sabido salir de las crisis con más Europa. En su actual estado y con la grave

${ }^{48}$ Propuesta de Directiva del Consejo, de 28 de septiembre de 2011, relativa a un sistema común del impuesto sobre las transacciones financieras y por la que se modifica la Directiva 2008/7/CE [COM(2011) 594 final.

Araucaria. Revista Iberoamericana de Filosofía, Política y Humanidades, año 19, n 37. Primer semestre de 2017. Pp. 427-454. ISSN 1575-6823 e-ISSN 2340-2199 doi: 10.12795/araucaria.2017.i37.20 
crisis política que sufre, la opción es que la evolución, más bien la involución, lleve a menos y peor Europa. Con sus errores y sus carencias, la Unión Europea sigue siendo un ejemplo de gobernanza e incluso de democracia trasnacional que, ojalá, nunca echemos de menos en un mundo que tanto necesita este tipo de actores. 


\section{Referencias bibliografía:}

Aldecoa, Francisco y Cornago, Noé (1998), "El nuevo regionalismo y reestructuración del sistema mundial", Revista Española de Derecho Internacional, vol. L, n. 1, pp. 59-113.

Aldecoa, Francisco y Guinea, Mercedes (2010), La Europa que viene: El Tratado de Lisboa, Madrid, Marcial Pons.

Alonso, Jose Antonio y Ocampo, José Antonio (eds.) (2015), Global Governance and Rules for the Post-2015 Era. Addressing Emerging Issues in the Global Environment, Nueva York, Bloomsbury Academic.

Barbé, Esther (2012), Cambio mundial y gobernanza global. La interacción entre la Unión Europea y las instituciones internacionales, Madrid, Tecnos.

Cardesa-Salzmann, Antonio y Pigrau Solé, Antoni (2017), "La Agenda 2030 y los Objetivos para el Desarrollo Sostenible. Una mirada crítica sobre su aportación a la gobernanza global en términos de justicia distributiva y sostenibilidad ambiental”, en Revista Española de Derecho Internacional, vol. 69, I, pp. 279-285.

González Alonso, Luis N. (director), Asier Garrido Muñoz (coordinador) (2011), La Unión Europea y el multilateralismo eficaz ¿Un compromiso consistente con Naciones Unidas?, Madrid, Iustel.

Mahon, Rianne y MacBride, Stephen (2009), "Standardizing and disseminating knowledge: the role of the OECD in global governance", European Political Science Review, Vol. 1, 1, pp. 83-101.

Martí Comas, Júlia (2016), "Gobernanza: la nueva matriz política del neoliberalismo", PAPELES de Relaciones Ecosociales y Cambio Global, Número 133, pp. 111-126.

Ocampo, José Antonio (editor) (2015), Gobernanza global y desarrollo. Nuevos desafios y prioridades de la cooperación internacional. Buenos Aires, Siglo XXI - CEPAL, pp. 65-66.

Olsen, Johan P. (2009), "Change and continuity: an institutional approach to institutions of democratic government, European Political Science Review, Vol. 1, 1, pp. 3-22.

Ortiz Martínez, Juan Sebastián (2016), La gobernanza en la cooperación internacional para el desarrollo. Instituto Universitario de Desarrollo y Cooperación (IUDC-UCM), Documento de Trabajo $\mathrm{n}^{\mathrm{o}} 38$, septiembre 2016.

Reichmann, Jorge (2015), en Autoconstrucción. La transformación cultural que necesitamos, Madrid, Los Libros de la Catarata. 
Salinas Alcega, Sergio (2013), "La acción de la Unión Europea en la Asamblea General de las Naciones Unidas: un test de su condición de actor global en materia de derechos humanos", en Antonio Blanc Altemir, Las relaciones entre las Naciones Unidas y la Unión Europea. Seguridad, cooperación y derechos humanos, Madrid, Tecnos, pp. 436-463.

Sotillo Lorenzo, José Ángel y Surasky, Javier Leonardo (2016), “Las relaciones entre Europa y América Latina en perspectiva decolonial ¿Encuentro o desencuentro?", Iberoamérica Social: revista-red de estudios sociales, VI, pp. 54 - 68. Recuperado en http:// iberoamericasocial.com/ las-relacioneseuropa-america-latina-perspectiva-decolonial-encuentro-desencuentro.

Sotillo Lorenzo, José Ángel (2017), "Desarrollo económico y sostenibilidad medioambiental: contribuciones de la Unión Europea a la definición de un orden internacional acorde a las necesidades del siglo XXI". Obra colectiva España y la Unión Europea en el orden internacional. Valencia, Tirant lo Blanch y Universidad de Sevilla, 2017, pp. 1225-1251.

Torreblanca, José Ignacio (2011), La fragmentación del poder europeo, Barcelona, Icaria.

Van Kersbergen, Kees, Van Waarden Frans (2004), “'Governance’ as a bridge between disciplines: Cross-disciplinary inspiration regarding shifts in governance and problems of governability, accountability and legitimacy", European Journal of Political Research, Vol. 43, 2, marzo 2004, pp. 143 171. 